\title{
Characterisation of fibre-reinforced backfill/ rock interface through direct shear tests
}

Xiangqian Xu

PhD candidate, College of Resources and Safety Engineering, China

University of Mining and Technology, Beijing, China; Department of Civil

Engineering, University of Ottawa, Ottawa, ON, Canada

Mamadou Fall

Professor and Associate Chair, Department of Civil Engineering, University

of Ottawa, Ottawa, ON, Canada (corresponding author: mfall@uottawa.ca)

\section{Imad Alainachi}

PhD candidate, Department of Civil Engineering, University of Ottawa, Ottawa, ON, Canada

Kun Fang

PhD candidate, Department of Civil Engineering, University of Ottawa, Ottawa, ON, Canada

This paper reports on the results of a laboratory investigation on the shear behaviour of the interface between granite rock and cemented paste backfill (CPB) reinforced with different amounts of fibre (F-CPB) and cured at room temperature for different lengths of time by performing direct shear tests. Moreover, various microstructural analysis techniques are also used to characterise the degree of cementation of the cemented matrix, as well as the microstructure of the interface. The results indicate that the shear properties and behaviour of the F-CPB/rock interface are a function of the fibre content (optimal fibre content) and reduce the contraction at the interface. It is also found that the optimal fibre content is a function of the curing time and applied normal stress. The shear strength envelopes indicate that the friction angle at the interface is larger in the sample that contains fibres, whereas fibre reinforcement reduces the interface adhesion. The results of this research will contribute to improvements in the design and stability assessments of fibre-reinforced cemented-backfill structures.

\section{Notation}

c cohesion or adhesion at the interface

$D_{10} \quad$ effective diameter

$G_{\mathrm{s}} \quad$ specific gravity

h height

$S_{\mathrm{s}} \quad$ specific surface area

$\gamma \quad$ effective unit weight

$\sigma_{\mathrm{n}} \quad$ normal stress

$\sigma_{\mathrm{v}}^{\prime} \quad$ vertical effective stress

$\tau \quad$ shear strength

$\phi \quad$ internal friction angle at the interface

\section{Introduction}

Cemented paste backfilling has received considerable interest in the mining industry worldwide over the past few decades, as it is a method that not only allows the reuse of up to $60 \%$ of the total amount of tailings (harmful soils generated from the processing of ore for extraction of minerals) produced to provide secondary ground support in underground mine stopes but also reduces ore dilution and surface subsidence to a large extent; it also enables management of tailings in a more environmentally friendly way (Ghirian and Fall, 2013, 2014; Nasir and Fall, 2008; Orejarena and Fall, 2008).

Cemented paste backfill (CPB) is usually composed of dewatered tailings ( $70-85 \%$ solids by weight), water and a hydraulic binder (2-10\% by dry mass of the tailings) (Nasir and Fall, 2009; Pirapakaran and Sivakugan, 2007). The strength and mechanical properties of CPB have always been key factors that determine the mechanical stability of CPB structures; they also significantly influence the design of CPB structures.
Therefore, the strength and mechanical characteristics of $\mathrm{CPB}$ and the factors that affect them have been the focus of many previous studies. For instance, Pokharel and Fall (2010) experimentally studied the impact of curing time, chemical composition of the pore water and temperature on the strength of $\mathrm{CPB}$ and established that there are coupled thermochemical effects on the strength of CPB. Yilmaz et al. (2014) established a relationship between the propagation velocity of ultrasonic waves through $\mathrm{CPB}$ samples and the strength of $\mathrm{CPB}$ samples that have been cured for different lengths of time by using an ultrasonic pulse velocity (UPV) test and showed the reliability of UPV in predicting the strength of CPB. Ercikdi et al. (2009) assessed the long-term strength of $\mathrm{CPB}$ that contains sulfide minerals and emphasised the importance of the binder type and content to ensure the durability of CPB that includes sulfide minerals. Fall and other scholars (Fall and Pokharel, 2010; Fall and Samb, 2009; Fall et al., 2009, 2010) analysed the effects of various factors, such as time, temperature and sulfate $\left(\mathrm{SO}_{4}{ }^{2-}\right)$, on the mechanical properties and microstructure of $\mathrm{CPB}$ and proposed a model to predict the physical and chemical properties of CPB. Liu et al. (2017) simulated the stress-and-strain behaviours of CPB under triaxial compression by using the Particle Flow Code (PFC2D) program and studied the effects of different particle size and porosity on the mechanical properties of $\mathrm{CPB}$. Previous studies on CPB have also shown that the strength of $\mathrm{CPB}$, and thus its mechanical stability, increases as the cement content is increased. However, a higher cement content will result in a more costly CPB design. Cement content can represent up to $75 \%$ of the total cost of CPB (Fall and Pokharel, 2010). Therefore, finding alternative means to reduce the binder content while maintaining or improving the mechanical stability of CPB structures is a key 
goal for mine backfill designers and mine operators. However, CPB structures that have low binder content are weak and can fail easily when subjected to stress from the overlying rock (Consoli et al., 2004; Ma et al., 2016; Nasir and Fall, 2008). To reduce the binder content and address the aforementioned brittleness of the $\mathrm{CPB}$, studies have proposed and investigated the effects of adding fibres into CPB (Mitchell and Stone, 1987).

A large number of studies have shown that the incorporation of fibres can increase the strength and toughness of cemented soil and other materials (e.g. concrete). The reinforcing effect of fibres is related to the type, length, shape and content of the fibres and the mechanical properties of the material itself (Consoli and Vendruscolo, 2009; Consoli et al., 2004, 2010; Correia et al., 2015; Diambra and Ibraim, 2015; Hamidi et al., 2013). However, CPB materials have different properties as opposed to cemented sand and soil and other materials due to their tailings mineral composition, particle size distribution and fill requirements. Mitchell and Stone (1987) conducted a limit equilibrium analysis and an accelerated model test on fibre-reinforced cemented backfill for the first time. The results indicated that the addition of fibres can effectively improve the stability of CPB and reduce the costs associated with using cement as a binder. Yi et al. (2015) studied the internal failure process of CPB reinforced with fibres (F-CPB) by subjecting samples to uniaxial compression testing and X-ray computed tomography scanning and found that incorporating fibres can result in an increase in the uniaxial compressive strength (UCS) by $70-90 \%$ and prevent the expansion and propagation of cracks in the CPB samples, which could indicate significantly higher toughness and durability.

The aforementioned studies provide useful information and technical data for better comprehension of the mechanical characteristics of $\mathrm{CPB}$ with or without fibres. However, no research has been done on the shear behaviour and characteristics of the interface between rock and CPB that contains fibres. An indepth understanding of the interaction between the CPB and the surrounding rock, in particular the shear characteristics or behaviour of the interface between the $\mathrm{CPB}$ and rock, is critical for assessing the arching effect in the CPB structure and thus essential for the optimal design of CPB structures. Indeed, when $\mathrm{CPB}$ is placed into an underground cavity (stope), in particular long narrow stopes with a ratio of length to width greater than 5, the microstratification of the CPB at different depths will result in sinking under the effect of self-weight. Compared with the CPB, the surrounding rock of the stope has higher rigidity, stiffness and strength (tens or even hundreds of times higher), so its vertical displacement is negligible. These two obviously different degrees of settlement will result in friction between the CPB and the surrounding rock, which in turn causes some of the self-weightinduced stress of the $\mathrm{CPB}$ to be transferred to the surrounding rock. The vertical and shear stresses of the $\mathrm{CPB}$ are lower than the stresses due to self-weight at this location, and as shown in Figure 1, this phenomenon is generally called the 'arching effect' (Fall and Nasir, 2010). Obviously, this arching effect is a function of the interface shear property of the CPB/rock (Liu, 2017). If the interface shear property of $\mathrm{CPB} /$ rock is not considered, the $\mathrm{CPB}$ and the surrounding rock will be tightly connected and cannot be separated, which will prevent the free deformation of CPB and result in an inaccurately estimated amount of arching. In turn, this could lead to an erroneous and/or costly design of the CPB, in which its failure can result in severe technical, economic and social repercussions (Fall and Nasir, 2010). However, the shear characteristics or behaviour of the interface between F-CPB and rock is known and understood. Therefore, a series of direct shear tests was performed in this study mainly to assess and understand this interface shear behaviour. The main goals of this paper are

- to study the time-dependent changes in the shear behaviour of the interface between the F-CPB and the rock

- to assess the effect of fibre content on the shear behaviour of the interface between the F-CPB and the rock

- to develop a good understanding of the shear behaviour of the interface between the F-CPB and the surrounding rock.

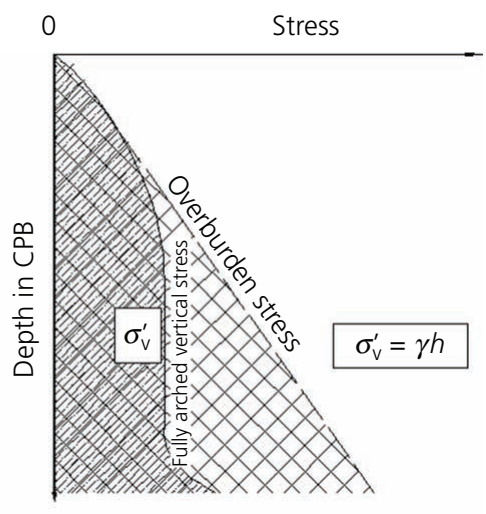

(b)

Figure 1. Schematic diagram of the arching effect: (a) arching and stress distribution in CPB mass; (b) arching and vertical stress distribution in CPB (Fall and Nasir, 2010) 


\section{Experimental programme}

\section{Materials used}

Tailings

Two kinds of tailings were used in this research (Figure 2). The first kind was silica tailings (ST), which are a kind of synthetic tailings (U.S. Silica Co.). The use of ST can minimise the uncertainties in the test results because using natural tailings (NT) would likely result in different initial chemical compositions of the $\mathrm{CPB}$, as NT commonly contain different types of reactive minerals that can oxidise during the storage of the tailings or the mixing of $\mathrm{CPB}$. This oxidation may generate sufficient sulfate ions that can deteriorate the long-term strength of the $\mathrm{CPB}$ through sulfate attack (the use of sulfate-resistant cements or binders can hinder the sulfate attack). Therefore, the use of ST would contribute to more accurate experimental results and better facilitate the accurate evaluation and interpretation of the experimental results ( $\mathrm{Li}$ and Fall, 2016; Wang et al., 2016). The second type was zinc tailings (ZT) that had been obtained from a zinc mine in eastern Canada. As shown in Figure 2(b), the ore processing water is retained in the $\mathrm{ZT}$ during the sampling process. Therefore, ZT have to be dried, pulverised, grounded and sieved before use. However, ZT contain some reactive chemical components (such as sulfides) that may react with the cement and its hydration products, as well as with other additives, which may affect the analysis of the experimental results (Table 1). The mineralogical composition and physical properties of the tailings used in this study are shown in Tables 1 and 2, respectively. It can be seen from Figure 3 that the grain size distribution of the ST is similar to that of NT and tailings from nine metal ore mines in Canada, which are medium tailings.

\section{Cement and mixing water}

The type of cement used in the experiment in this study was ordinary Portland cement type I (PCI; Ciment Québec Inc.). The main chemical and physical characteristics of PCI are listed in Table 3.

In the experiment in this study, tap water with a $\mathrm{pH}$ of 7.5 was used as the mixing water. The chemical composition of the tap water is provided in Table 4 .

\section{Rock samples}

The rock used for the experiment is medium-grain granite. It has an average UCS of $160 \mathrm{MPa}$. A large piece of granite rock was
Table 1. Mineralogical composition of tailings used in study

\begin{tabular}{lrc} 
Mineral & ST & ZT \\
\hline Quartz: $w t \%$ & 11.9 & 99.8 \\
Albite: $w$ t\% & $1 \cdot 2$ & - \\
Dolomite: $w t \%$ & $5 \cdot 7$ & - \\
Calcite: $w t \%$ & $2 \cdot 2$ & - \\
Chlorite: $w t \%$ & $18 \cdot 2$ & - \\
Magnetite: $w t \%$ & $11 \cdot 4$ & - \\
Pyrite: $w t \%$ & $15 \cdot 4$ & - \\
Talc: $w t \%$ & $16 \cdot 4$ & - \\
Magnesite: $w t \%$ & $7 \cdot 6$ & - \\
Pyrrhotite: $w t \%$ & $3 \cdot 1$ & - \\
Spinel: $w t \%$ & $3 \cdot 2$ & $0 \cdot 2$ \\
Others: $w t \%$ & $3 \cdot 7$ & $100 \cdot 0$ \\
Total: $w t \%$ & $100 \cdot 0$ &
\end{tabular}

Table 2. Physical characteristics of tailings used in study

$\begin{array}{lccrccc}\text { Tailings } & \boldsymbol{G}_{\mathbf{S}} & \boldsymbol{D}_{\mathbf{1 0}}: \boldsymbol{\mu m} & \boldsymbol{D}_{\mathbf{3 0}}: \mu \mathrm{m} & \boldsymbol{D}_{\mathbf{5 0}}: \mu \mathrm{m} & \boldsymbol{D}_{\mathbf{6 0}}: \mu \mathrm{m} & \boldsymbol{S}_{\mathbf{s}}: \mathbf{c m}^{\mathbf{2}} \mathbf{g} \\ \text { ST } & 2.7 & 1.9 & 9.0 & 22.5 & 31.5 & 3600 \\ \text { ZT } & 3.3 & 1.6 & 10.9 & 29.9 & 37.8 & 2772\end{array}$

$G_{s}$, specific gravity; $S_{\mathrm{s}}$, specific surface area

cut into samples with dimensions of $60 \times 60 \times 8 \mathrm{~mm}$ by using a rock cutter. Subsequently, the surface of the samples was polished. The surface roughness was determined by using a highprecision linear variable differential transformer (LVDT) before the interface shear test was carried out. According to the profile roughness parameter (Gokhale and Underwood, 1990), the rock surface that is in contact with the $\mathrm{CPB}$ is smooth and flat. It should be underlined that the effect of rock surface roughness on the interface shear behaviour between fibre-reinforced CPB and rock is outside the scope of the present study.

\section{Fibres}

The fibres used in the experiment were bundles of monofilament polypropylene fibres (Ignis (Adfil)), which are a crystalline material with an orderly structure and a white or milky white colour (Figure 4). These fibres have extremely low water absorption and good chemical stability. They are also acid, alkali and corrosion resistant. These fibres can be well mixed with other types of cements to enhance their strength and durability (Yi et al., 2015). The Ignis fibres have a $6 \mathrm{~mm}$ length, a diameter of

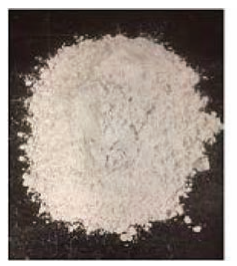

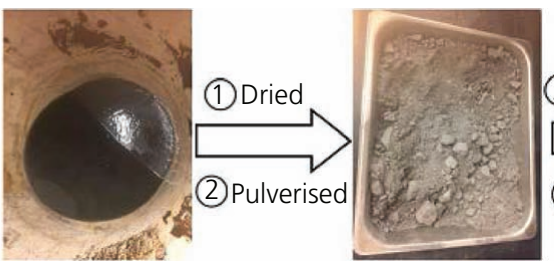

(a)

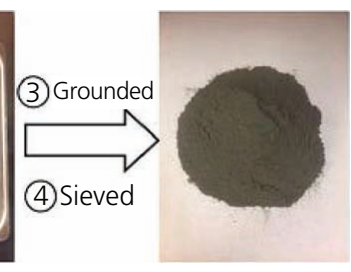

(b)

Figure 2. Tailings used in study: (a) ST; (b) ZT 
Characterisation of fibre-reinforced

backfill/rock interface through direct

shear tests

Xu, Fall, Alainachi and Fang

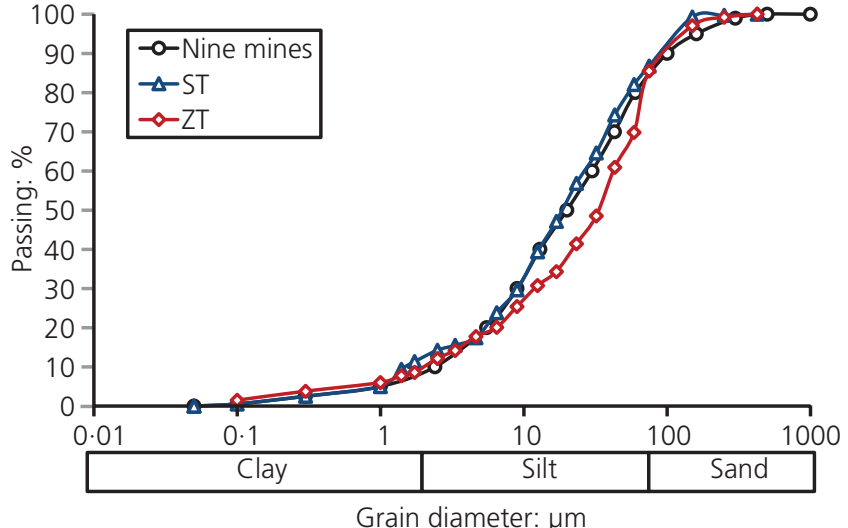

Figure 3. Grain size distributions of tailings: this study's tailings compared against tailings from nine metal ore mines in eastern Canada

$18 \mu \mathrm{m}$ and a specific gravity of $0 \cdot 91$. Their tensile strength can be up to $600 \mathrm{MPa}$. Based on the results of previous studies on CPB that incorporates fibre (Consoli et al., 2011; Zaimoglu and Yetimoglu, 2012), the compressive strength of the CPB can be significantly increased when the fibre content is between 0.25 and $0.75 \%$ (by dry mass). Consequently, the fibre contents selected in this investigation were $0 \cdot 0,0 \cdot 2,0 \cdot 3$ and $0 \cdot 5 \%$ by mass of the sum of the dry tailings and cement. It should be emphasised that the objective in this investigation is not the development of optimal fibre content for $\mathrm{CPB}$.

\section{Sample preparation and curing}

In preparing the F-CPB samples, the required amounts of cement, tailings and Ignis fibres were first weighed separately. Then, they were added to a mixing container and mixed uniformly. Finally, mixing water was added to the container and then the entire mixture was stirred for approximately $7 \mathrm{~min}$ to obtain a homogeneous paste. After putting the granite into plastic square moulds with sizes of $60 \times$ $60 \times 30 \mathrm{~mm}$, the prepared F-CPB was poured on the top of the granite. Subsequently, the plastic container was manually vibrated to eliminate the air bubbles that had been formed in the F-CPB or

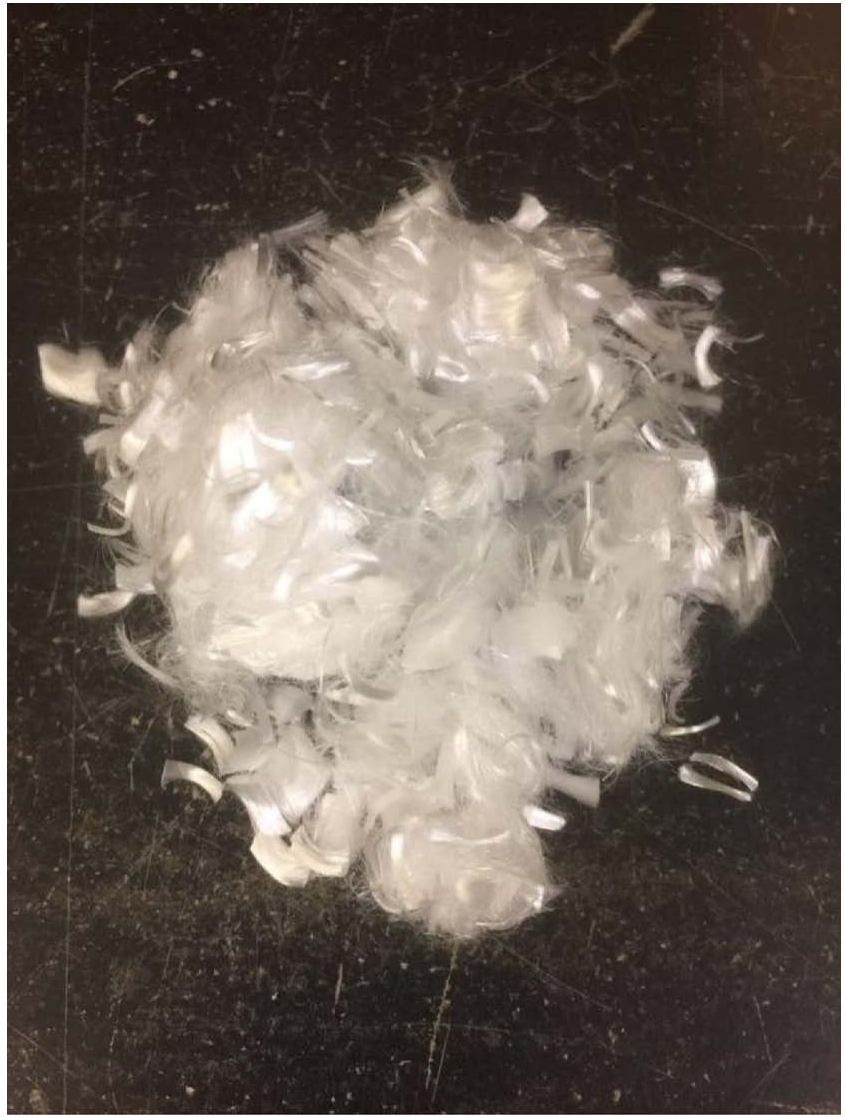

Figure 4. Ignis (Adfil) fibres

interface of the samples. The container was then covered with plastic wrap (to avoid the evaporation of water) and then moved to an environmental chamber (room temperature or $\left.\sim 20^{\circ} \mathrm{C}\right)$ for curing $(1,3$ and $7 \mathrm{~d}$ ). After curing for the targeted amount of time and just before the shear testing was started, the samples were removed from the moulds and wrapped with plastic wrap and labelled with numbers (Figure 5). The composition of the mixture and curing time and temperature of the interface of the samples prepared are shown in Table 5. Over 70 samples were prepared.

Table 3. Main chemical and physical characteristics of the PCI used (Pokharel and Fall, 2010)

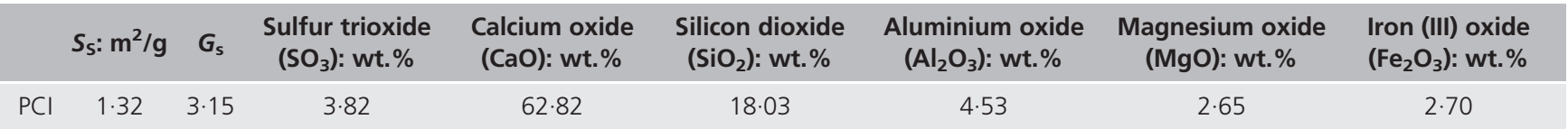

$G_{S}$, specific gravity; $S_{S}$, specific surface area

Table 4. Chemical composition of the tap water used (chemical composition determined by inductively coupled plasma emission spectroscopy analysis)

\begin{tabular}{|lccccccc} 
& $\begin{array}{c}\text { Iron } \\
(\mathrm{Fe})\end{array}$ & $\begin{array}{c}\text { Calcium } \\
(\mathbf{C a})\end{array}$ & $\begin{array}{c}\text { Aluminium } \\
(\mathbf{A l )}\end{array}$ & $\begin{array}{c}\text { Silicon } \\
(\mathrm{Si})\end{array}$ & $\begin{array}{c}\text { Sodium } \\
(\mathbf{N a})\end{array}$ & $\begin{array}{c}\text { Magnesium } \\
(\mathbf{M g})\end{array}$ & $\begin{array}{c}\text { Manganese } \\
(\mathbf{M n})\end{array}$ \\
\hline Concentration: parts per million & 0.03 & 46.60 & 0.13 & 0.64 & 5.30 & 2.60 & 0.00 \\
$\left(\mathbf{S O} \mathbf{4}^{2-}\right)$
\end{tabular}


Characterisation of fibre-reinforced backfill/rock interface through direct shear tests

Xu, Fall, Alainachi and Fang

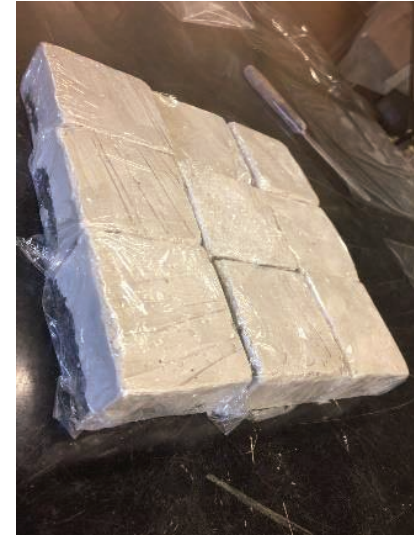

(a)

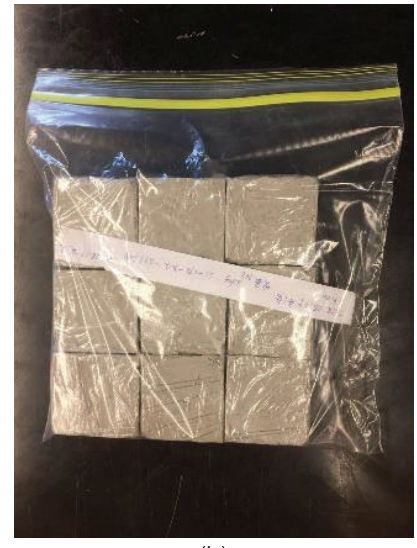

(b)
Figure 5. F-CPB/ rock interface samples: (a) wrapped with plastic film; (b) labelled with numbers

\section{Interface shear tests}

A strain-controlled direct shear device was used to evaluate the shear behaviour and shear strength at the interface between the $\mathrm{F}-\mathrm{CPB} /$ rock in this research, as shown in Figure 6. During the experiment, the sample was inserted into the shear box of the shear device, as shown in Figure 7. The shear box had an upper and a lower half. The upper half of the shear box held the F-CPB part of the sample, and the lower half contained the granite part of the sample. Then, after applying a certain amount of normal stress $(50,100$ and $150 \mathrm{kPa})$, the sample was sheared at a constant shear rate until the sample broke. After failure of the sample, shearing was performed until a stable shear stress value (residual strength) was obtained. The shear rate was $0.5 \mathrm{~mm} / \mathrm{min}$, which is similar to that used in previous studies (Nasir and Fall, 2008). The maximum shear displacement in this experiment was $6 \mathrm{~mm}$. Each shear test was conducted at least twice to ensure the repeatability of the results. All of the data (e.g. shear force and shear and normal displacements) were recorded by using a computerised data-logging system. The results were monitored and saved by using the computer software called LabView.

\section{Microstructural analysis}

Two microstructural analysis techniques - namely, thermal gravimetric (TG)/differential thermal gravimetric (DTG) analyses

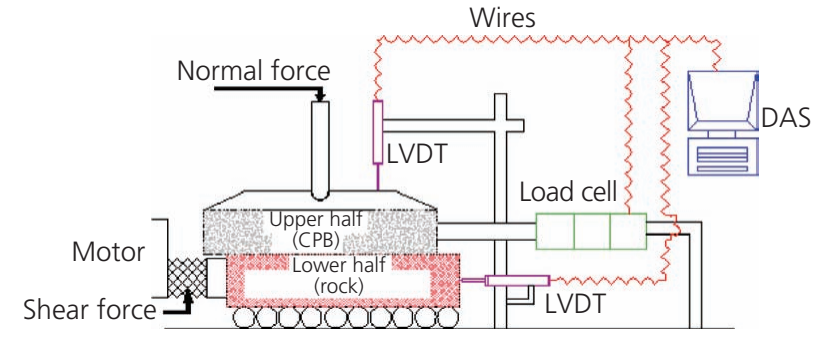

Figure 6. Schematic diagram of direct shear device (Fall and Nasir, 2010). DAS, data-acquisition system

and scanning electron microscopy (SEM) observation - were used to assess the time-dependent evolution of the microstructure (binder hydration products, pore structure) of the F-CPB and the interface. All of the samples that were subjected to a microstructural analysis were first dried in an oven at $45^{\circ} \mathrm{C}$ to eliminate the free water. Drying at this temperature did not create microcracks in the samples.

The TG/DTG analyses were conducted on the cement paste of $\mathrm{F}-\mathrm{CPB}$ with a water/cement ratio of 1 (to mimic the high water content of F-CPB) by using a Q5000IR TG analyser and a differential scanning calorimeter (TA Instruments SDT) to

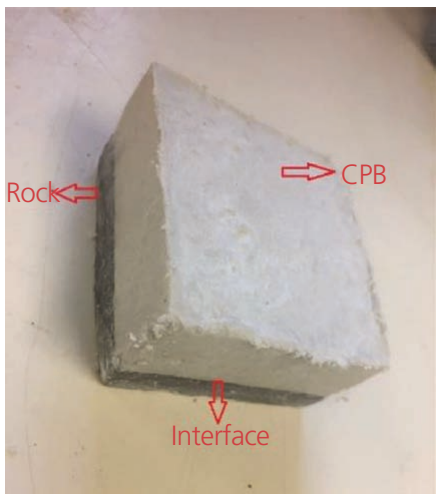

(a)

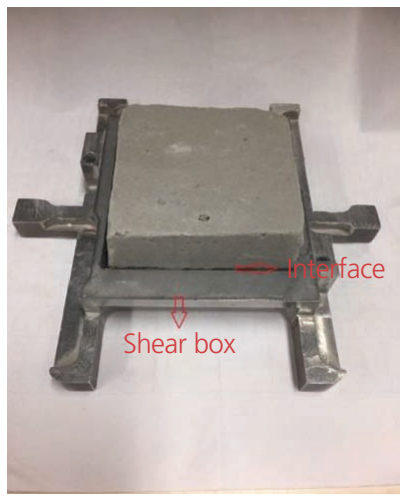

(b)
Figure 7. Sample (a) before and (b) after being placed into the shear box

Table 5. Mixture composition, curing time and temperature of prepared samples

\begin{tabular}{|c|c|c|c|c|c|c|c|c|}
\hline $\begin{array}{l}\text { Sample } \\
\text { number }\end{array}$ & $\begin{array}{l}\text { Tailings } \\
\text { type }\end{array}$ & Binder & $\begin{array}{c}\text { Binder } \\
\text { content: \% }\end{array}$ & $\begin{array}{c}\text { Fibre } \\
\text { content: \% }\end{array}$ & $\mathrm{W} / \mathrm{C}$ & $\begin{array}{c}\text { Curing } \\
\text { temperature: }{ }^{\circ} \mathrm{C}\end{array}$ & $\begin{array}{l}\text { Curing } \\
\text { time: } d\end{array}$ & $\begin{array}{c}\text { Number of } \\
\text { samples }\end{array}$ \\
\hline CPB/rock 1 & ST & $\mathrm{PCl}$ & 4.5 & 0.5 & $7 \cdot 35$ & 20 & $1,3,7$ & 18 \\
\hline CPB/rock 2 & $\mathrm{ZT}$ & $\mathrm{PCl}$ & $4 \cdot 5$ & 0.5 & $7 \cdot 35$ & 20 & 1 & 6 \\
\hline CPB/rock 3 & ST & $\mathrm{PCl}$ & $4 \cdot 5$ & 0.0 & $7 \cdot 35$ & 20 & 1 & 6 \\
\hline CPB/rock 4 & $\mathrm{ZT}$ & $\mathrm{PCl}$ & 4.5 & 0.0 & $7 \cdot 35$ & 20 & 1 & 6 \\
\hline СРB-СРB 1 & ST & $\mathrm{PCl}$ & 4.5 & 0.5 & $7 \cdot 35$ & 20 & 1 & 6 \\
\hline CPB/rock 5 & ST & $\mathrm{PCl}$ & $4 \cdot 5$ & 0.3 & $7 \cdot 35$ & 20 & $1,3,7$ & 18 \\
\hline CPB/rock 6 & ST & $\mathrm{PCl}$ & 4.5 & 0.2 & $7 \cdot 35$ & 20 & $1,3,7$ & 18 \\
\hline
\end{tabular}

$\mathrm{PCl}$, Portland cement type I; ST, silica tailings; W/C, mass of water divided by mass of binder; ZT, zinc tailings 
examine the progression of the cement hydration and the volume of hydration products formed in the F-CPB materials. The dried samples were heated to $1000^{\circ} \mathrm{C}$ at a rate of $10^{\circ} \mathrm{C} / \mathrm{min}$, and the weight changes, heat flow and temperature transitions were recorded accordingly.

The SEM observations were performed using a Hitachi 3500-N microscope to characterise the pore structure at the interface between the rock and the F-CPB. Different magnifications were used to examine the transition zone at the interface.

\section{Results and discussion}

Figure 8 shows typical (representative) shear stress-shear displacement curves of the interface between the F-CPB and the rock samples cured for $1 \mathrm{~d}$ ( $1 \mathrm{~d} \mathrm{F-CPB/rock} \mathrm{interface)} \mathrm{under} \mathrm{a}$ normal stress of $150 \mathrm{kPa}$ for different fibre contents. It can be observed that all of the curves have a similar pattern irrespective of the kind of tailings. Figure 8(a) shows that the curves all have three phases or stages (taking as examples the curves of the samples with fibre contents of 0 and $0 \cdot 2 \%$ - the former is $\mathrm{OABC}$ and the latter is $\left.\mathrm{OA}^{\prime} \mathrm{B}^{\prime} \mathrm{C}^{\prime}\right)$. The first stage $\left(\mathrm{OA}\right.$ or $\left.\mathrm{OA}^{\prime}\right)$ can be regarded as the linear elasticity stage, in which the shear stress linearly rises with an increase in the shear displacement. There is no significant difference in the slope of all of the curves at this stage, thus indicating that the fibres have no significant influence on the initial stiffness at the interface of the samples. This finding is consistent with the conclusions made in the study by Ma et al. (2016) on fibre-reinforced cementitious material or soils, which indicated that the initial stiffness of fibre-reinforced soils is not influenced by the fibres but is significantly affected by cementation. At this stage, the interface shear behaviour is mainly governed by the CPB matrix itself, and the fibres do not significantly contribute to this behaviour yet. The second stage $\left(\mathrm{AB}\right.$ or $\left.\mathrm{A}^{\prime} \mathrm{B}^{\prime}\right)$ is the plastic stage, and as the shear displacement continues to increase, the shear stress gradually increases until it reaches the interface shear strength or the initiation of the peak shear stress at a shear displacement of about $1 \cdot 0-1 \cdot 3 \mathrm{~mm}$. The curves at this stage show non-linearity. Moreover, the interface of the fibre-reinforced backfill generally shows a higher shear stress than those without fibre reinforcement. In other words, the slope of the stress-strain curve of the interface of fibre-reinforced backfill is generally slightly higher because the presence of fibres inhibits the propagation of microcracks and increases the local stress required to break the microasperities on the surface of the $\mathrm{F}-\mathrm{CPB}$ due to the reinforcement effect of the fibres (Nasir and Fall, 2008). The third stage ( $\mathrm{BC}$ or $\left.\mathrm{B}^{\prime} \mathrm{C}^{\prime}\right)$ is the post-destruction stage, and as the shear displacement continues to increase, the shear stress gradually becomes constant (residual shear strength). At this stage, the F-CPB/rock interface has less strength loss than the $\mathrm{CPB} /$ rock interface with no fibres. The process responsible for this lower strength loss is discussed later. A comparison of Figures $8(a)$ and 8 (b) reveals that the interface samples with NT have a lower peak stress and residual strength than those with ST. The lower values observed for the samples made with NT are due to the fact that NT contain sulfate ions ( $~ 5000$ parts per million). Sulfate ions inhibit cement hydration, which obviously leads to lower strength values, as proven in many previous studies on cementitious materials (CPB, concrete etc. (Ercikdi et al., 2009; Fall and Pokharel, 2010; Li and Fall, 2016)).

Further analysis of Figure 8 shows that the peak shear stresses of the granite rock and F-CPB interface with $0 \cdot 2,0 \cdot 3$ and $0 \cdot 5 \%$ fibre contents are $10 \%$ higher than, $5 \%$ higher than and similar to that of the samples with no fibres, respectively. Moreover, the samples with a fibre-reinforced interface have higher residual strength than the samples without added fibres. A fibre content of $0 \cdot 2 \%$ results in the highest peak and residual strengths. These results on the impact of fibre content on the interface shear strength indicate that the shear strength of the $1 \mathrm{~d} \mathrm{F-CPB/rock} \mathrm{interface} \mathrm{(i.e.} \mathrm{at} \mathrm{a} \mathrm{very}$ early age) and fibre content is not a simple linear relationship. Indeed, there is a critical value beyond which the shear strength decreases as the fibre content is increased. Similar conclusions

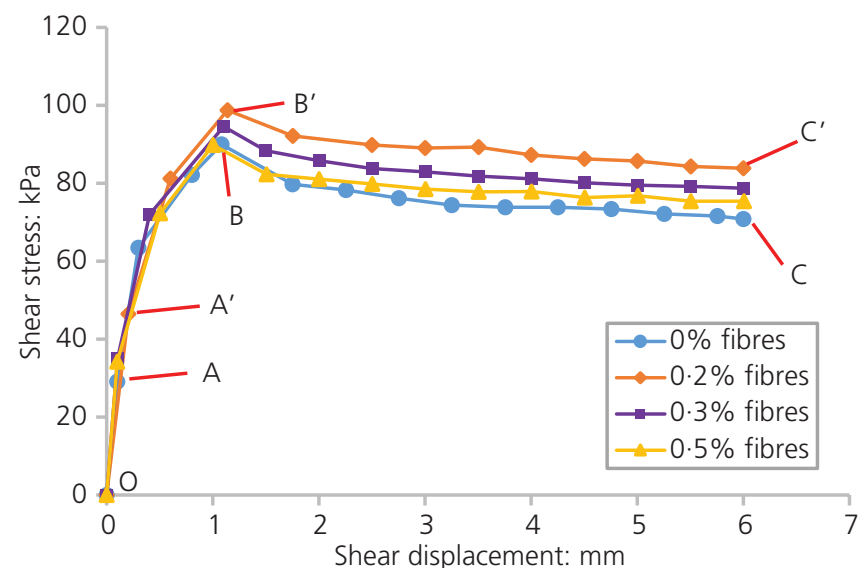

(a)

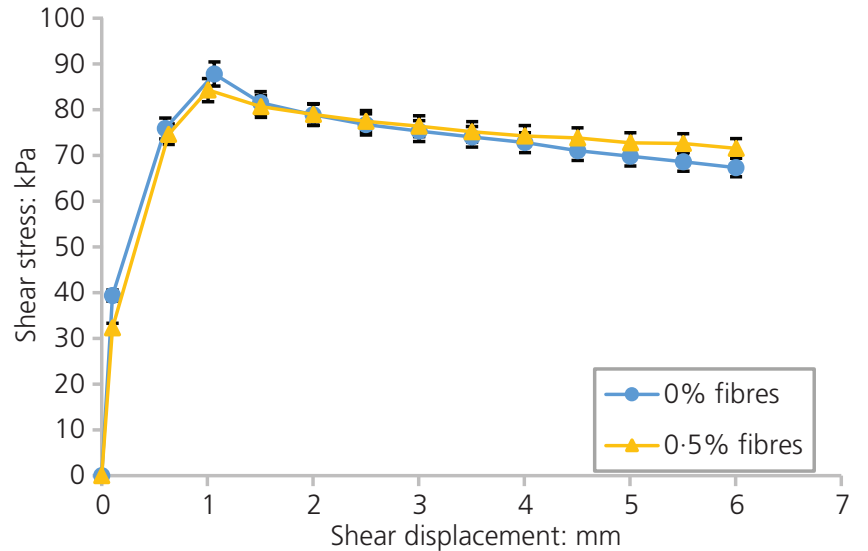

(b)

Figure 8. Shear stress plotted against shear displacement of the $1 \mathrm{~d}$ F-CPB/rock interface under a normal stress of $150 \mathrm{kPa}$ for different fibre contents: (a) CPB made with ST; (b) CPB made with ZT 
Characterisation of fibre-reinforced

backfill/rock interface through direct

shear tests

Xu, Fall, Alainachi and Fang have been made in past studies on soils reinforced with fibres. For example, Prabakar and Sridhar (2002) observed that when the sisal fibre content is greater than $0 \cdot 75 \%$, the shear strength of soil starts to decrease. Akbulut et al. (2007) studied the unconfined compressive strength of clayey soils reinforced with scrap tyre rubber and synthetic fibres and noticed that when the fibre content exceeds $0 \cdot 2 \%$, the unconfined compressive strength starts to decline. Cai et al. (2006) studied the mechanical properties of fibre-lime-treated soils and, by using a direct shear test, obtained the optimal fibre content, which is $0.3 \%$ of the dry soil weight. Wu and Zhang (2011) showed that the shear strength of expansive soil with polypropylene fibres incorporated first increases and then decreases with the fibre content, and the corresponding optimal fibre content is $0 \cdot 3 \%$

The optimal fibre content is related to the reinforcing ability of the fibres. When a small amount of fibres is added, the fibres are easily dispersed throughout the CPB. The interfacial force between the fibres and the CPB particles will inevitably prevent the relative sliding of the fibres, so that the fibres can resist a certain amount of shear stress, thus sharing the external load. Moreover, when the fibres are stressed, they restrain the CPB particles at the bend of the fibres, limit the deformation of the $\mathrm{CPB}$ and contribute to improving the overall shear mechanical properties of the $\mathrm{F}-\mathrm{CPB} /$ rock interface. When a large volume of fibres is added, the fibres might adhere to each other in partial agglomeration, which reduces the dispersion of the fibres in the CPB (Wang et al., 2013). This results in an inhomogeneous distribution of fibres in the $\mathrm{CPB}$ and their reduced contact with the $\mathrm{CPB}$ particles (tailings, cement hydration products), as well as an increase in the microdefects of the backfill materials (Akbulut et al., 2007), thereby reducing the interface shear strength. In addition, CPB particles, in particular cement hydration products (e.g. calcium silicate hydrate (C-S-H) and calcium hydroxide $(\mathrm{CH})$ ), on the $\mathrm{F}-\mathrm{CPB} /$ rock interface could be replaced with fibres, which means that the effective contact area between the cementitious matrix of the F-CPB and the rock will be inevitably reduced. As a result, the cohesion between the F$\mathrm{CPB}$ and the rock is also reduced (as shown in Figure 17(b)), which is not favourable to the interface shear strength. This replacement of the cement hydration products or cemented matrix of F-CPB at the interface is experimentally supported by the SEM image of the $1 \mathrm{~d}$ F-CPB/rock interface presented in Figure 9. This figure shows the presence of fibres at the interface, particularly between the surface of the rock and that of the cemented matrix of the backfill, which will obviously lead to a reduction in the cohesion or adhesion at the interface.

The results discussed in the preceding paragraphs indicate that, although the addition of fibres in general increases the shear strength of the $1 \mathrm{~d} \mathrm{F-CPB/rock} \mathrm{interface,} \mathrm{this} \mathrm{fibre-induced}$ increase in the interface shear strength (up to $10 \%$ ) is small compared with the increase in the strength (UCS) of the soil or $\mathrm{CPB}$ alone due to the addition of fibres. Previous studies (Ma et al., 2016; Tang et al., 2007; Yi et al., 2015) have reported that the addition of fibres can significantly increase the UCS of fibrereinforced soils and fibre-reinforced CPB (up to 70-90\%).

Figure 10 presents the typical vertical displacement plotted against the shear displacement of the $1 \mathrm{~d}$ F-CPB/rock interface under a normal stress of $150 \mathrm{kPa}$ for different fibre contents. As can be seen from the figure, the $1 \mathrm{~d}$ interface samples show a contractive behaviour irrespective of the fibre content and type of tailings under an applied normal stress of $150 \mathrm{kPa}$. No dilative behaviour is observed. The contraction is particularly considerable at the

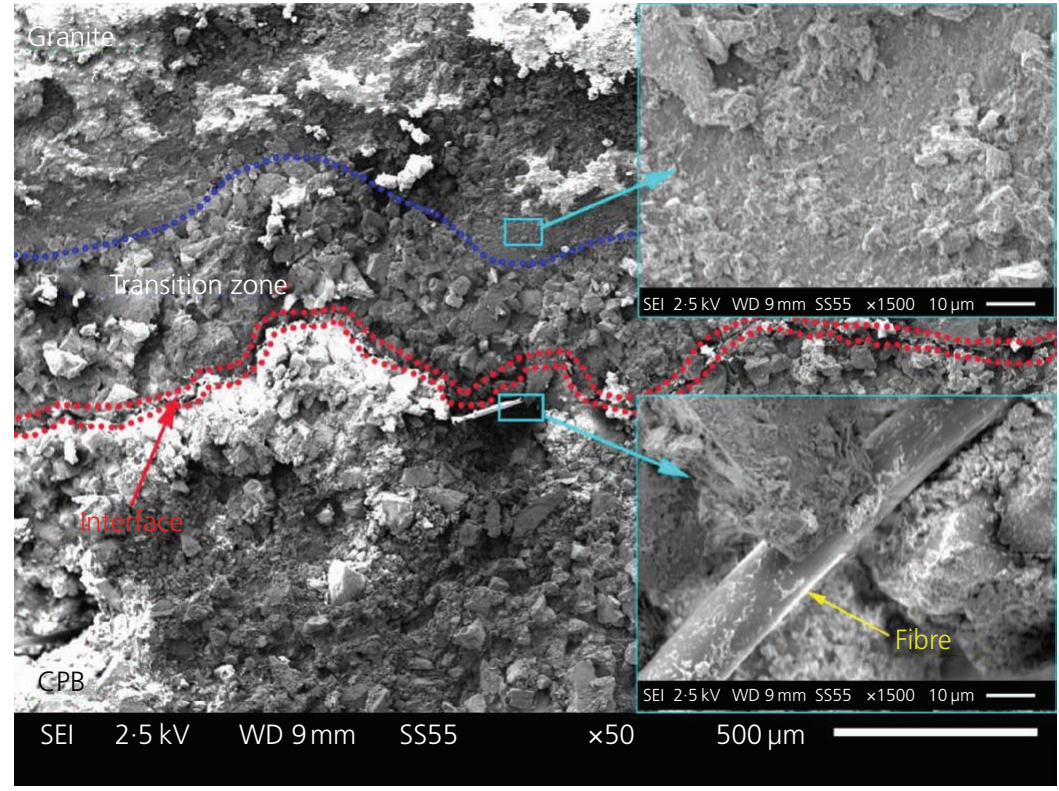

Figure 9. SEM image of the $1 \mathrm{~d}$ F-CPB/rock interface 

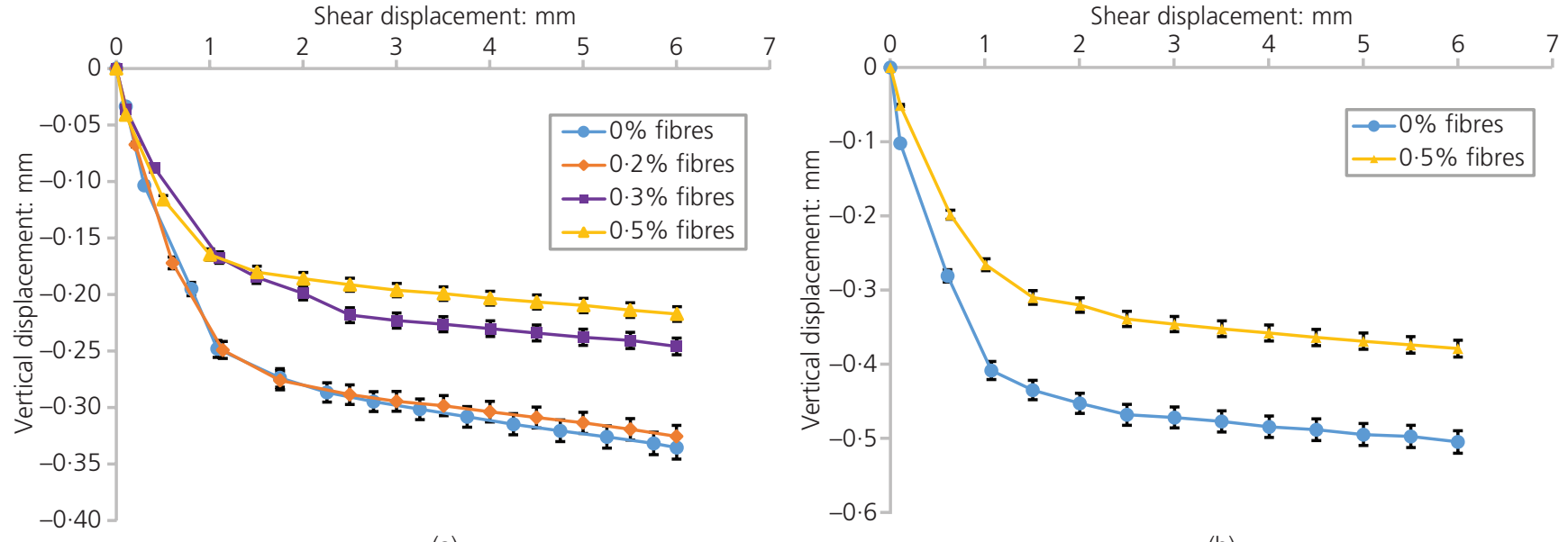

(a)

(b)

Figure 10. Vertical displacement-shear displacement plot of the $1 \mathrm{~d} \mathrm{F-CPB/rock} \mathrm{interface} \mathrm{under} \mathrm{a} \mathrm{normal} \mathrm{stress} \mathrm{of} 150 \mathrm{kPa}$ for different fibre contents: (a) CPB made with ST; (b) CPB made with ZT

beginning of the shearing (shear displacement $\leq \sim 1.0 \mathrm{~mm}$ ) and then is reduced as the shearing continues. This high contraction that is found early on is due to the fact that when the F-CPB material is cured for a very short period of time $(1 \mathrm{~d})$, the cementation of the tailings particles and fibres is weak due to the few hydration products (e.g. C-S-H and $\mathrm{CH}$ ) produced by cement hydration. Accordingly, at the start of the loadings, more contact between the fibres and tailings particles, between the tailings or between the fibres themselves and between the fibres or tailings particles and the rock developed, and the size of the local voids was reduced (Nasir and Fall, 2008). In addition, at the early ages, the backfill material has high compressibility, which contributes to the observed contracting behaviour (Fall and Nasir, 2010). The significantly fewer contractions and non-dilative behaviour observed at the later stages of shearing can be explained by the coupled effects of two factors: $(a)$ the initial contraction significantly reduces the void size of the F-CPB and (b) the shear loadings in this stage have damaged the asperities on the surface of the F-CPB, which are still weak at the early ages of cement hydration (Nasir and Fall, 2008). However, it should be emphasised that the amount of contraction and dilation is a function of the applied normal stress, as observed in previous studies on the behaviour of the interface between rock and soils or rock and cemented materials, which is shown in Figure 14 and discussed later. It can also be noticed in Figure 10 that the interface samples with NT show larger contraction than those with ST. The reason for this behaviour is, as explained previously, the inhibition of cement hydration due to the presence of sulfate ions in the NT, which increases the compressibility of the samples made with NT.

Moreover, Figure 10 also shows that the total vertical displacement or contraction of the fibre-reinforced interface sample is smaller than that of the sample without fibres, and the amount of deformation is reduced as the fibre content is increased. This can be due to the fact that the presence of fibres inhibits the rearrangement and settlement of the tailings particles, which macroscopically reduces the compressibility and prevents the further deformation of the F-CPB material. When a small volume of fibre is added, there are large voids between the fibres or fibres and tailings, and an effective fibre matrix cannot be formed. As the fibre content is increased, a large number of fibres are interwoven into a matrix, which not only fills the microcracks or capillary pores in the $\mathrm{CPB}$ but also prevents the deformation and compressibility of the CPB. These arguments are consistent with the results of Starcher and Liu (2013) on the mechanical behaviour of soft soil improved with cement and fibres. They concluded that the addition of cement and fibres reduces the compressibility of soft soil.

Typical shear strength envelopes for the $1 \mathrm{~d}$ F-CPB/rock interface are shown in Figure 11. These envelopes have been developed by fitting linear regression lines through each set of interface shear stress against normal stress data points at the interface. From the figure, it can be seen that all of the correlation coefficients $R^{2}$ of the envelope curves are higher than 0.98 , and a good linear correlation between the shear strength and the normal stress can be found. Thus, the shear envelope can be described by using the Mohr-Coulomb failure criterion

1. $\tau=\sigma_{\mathrm{n}} \tan \phi+c$

where $c$ and $\phi$ are the cohesion or adhesion and internal friction angle at the interface, respectively. The values of $c$ and $\phi$ are calculated and shown in Table 6.

From Figure 11 and Table 6, it can be also noticed that the presence of fibres slightly increases the internal friction angle of the $1 \mathrm{~d}$ interfaces studied. However, a high proportion of fibres $(0 \cdot 5 \%)$ significantly reduces the cohesion at the interface due to the reasons explained previously. This figure and table also confirm the 


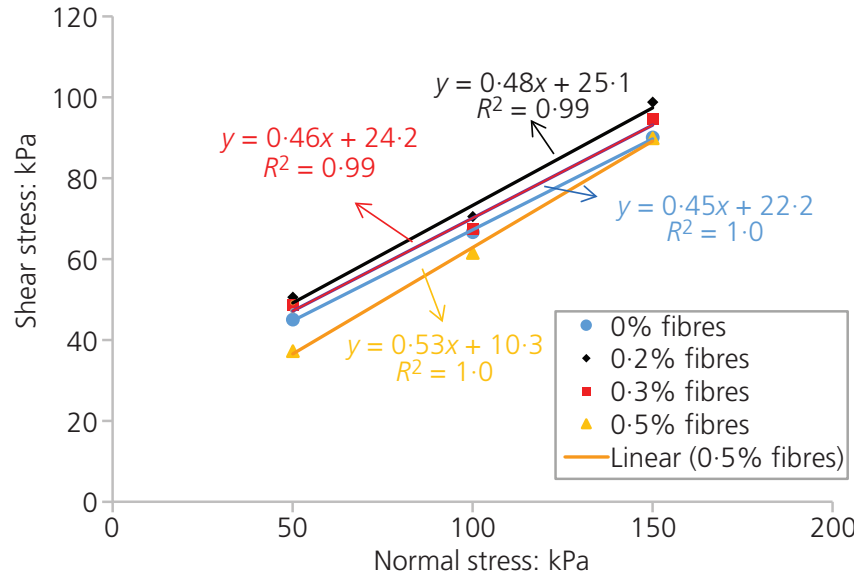

(a)

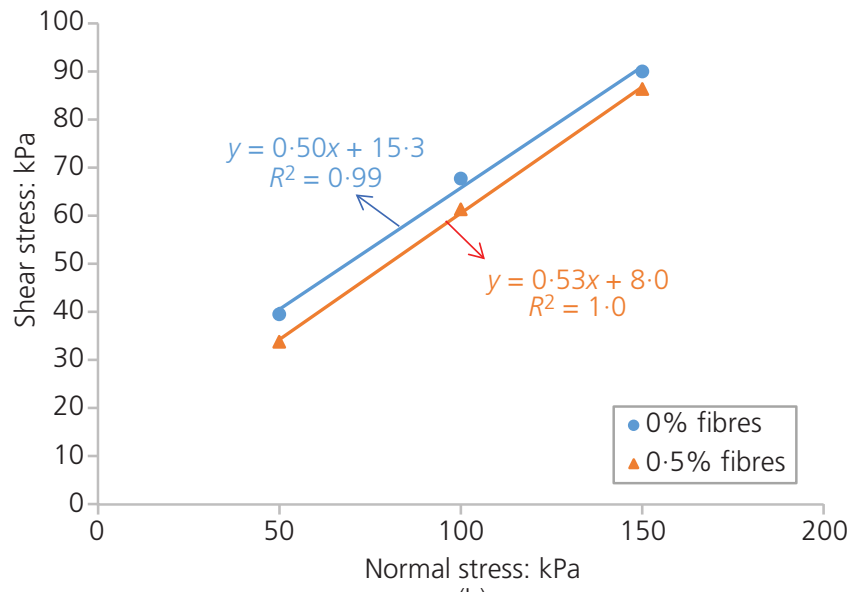

(b)

Figure 11. Shear stress-normal stress plots of the $1 \mathrm{~d}$ F-CPB/rock interface: (a) F-CPB made with ST; (b) F-CPB made with ZT

previous conclusion that after a certain (threshold) fibre content, the increase in fibre content reduces the cohesion at the $1 \mathrm{~d}$ interface.

Figure 12 shows typical shear-stress-against-shear-displacement curves of the F-CPB/rock interface with $0 \cdot 3 \%$ fibre content for different curing times under different normal stresses. It is obvious that the curing time significantly influences the shear characteristics of the F-CPB/rock interface, and a longer curing time means higher shear strength. This is because a longer curing time results in a higher degree of cement hydration - that is, more cement hydration

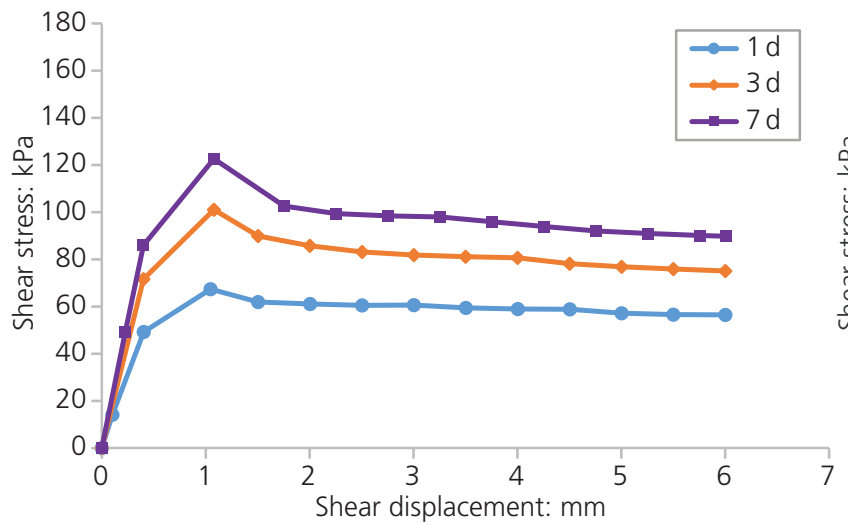

(a)

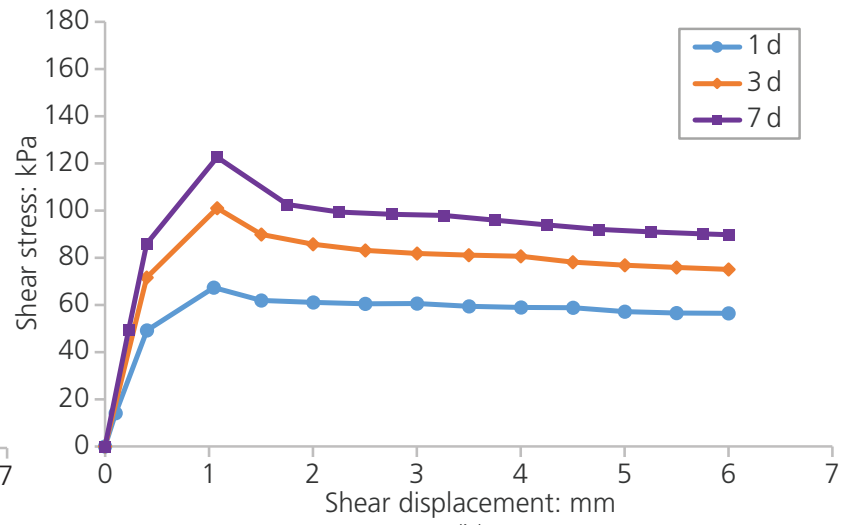

(b)

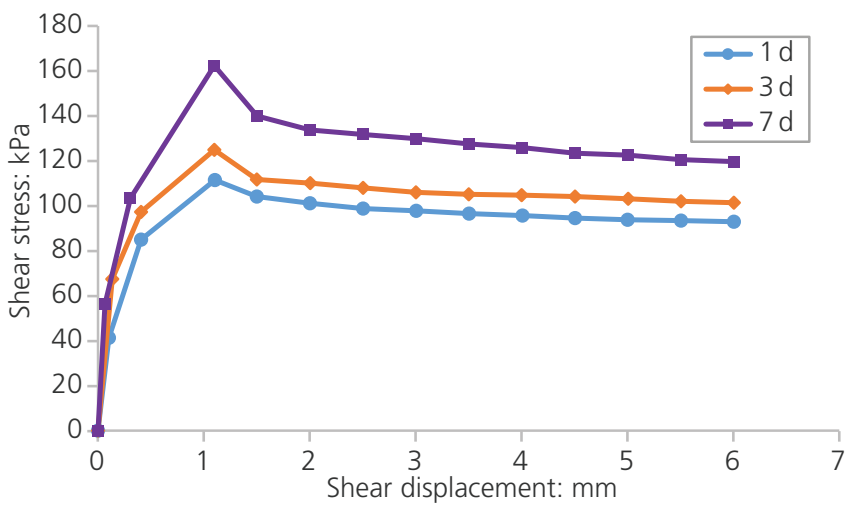

(c)

Figure 12. Shear stress-shear displacement plots of the of CPB/rock interface with $0.3 \%$ fibre content for different curing times under different normal stresses: (a) $50 \mathrm{kPa}$; (b) $100 \mathrm{kPa}$; (c) $150 \mathrm{kPa}$ 
Characterisation of fibre-reinforced

backfill/rock interface through direct

shear tests

Xu, Fall, Alainachi and Fang

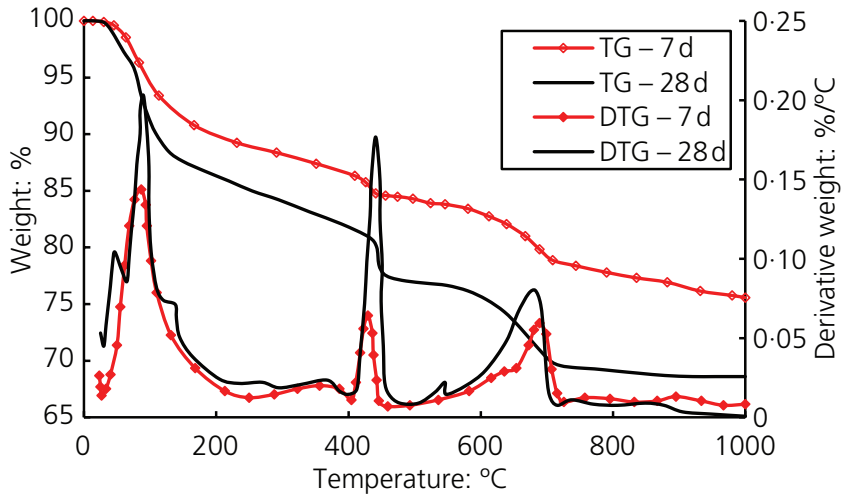

Figure 13. TG/DTG analyses of cemented paste of F-CPB samples cured for 7 and $28 \mathrm{~d}\left(20^{\circ} \mathrm{C}\right)$

products will be formed (Fall et al., 2010). As a result, on the one hand, there is a greater adhesion between the F-CPB material and the granite rock (which increases the interface cohesion) and, on the other hand, the hardness of the asperities on the surface of the F-CPB will increase (which increases the interface friction strength during the shear process (Fall and Nasir, 2010)). According to the aforementioned Mohr-Coulomb failure criterion, shear strength mainly consists of two types - namely, cohesive and friction forces. Therefore, a longer curing time leads to higher shear strength at the $\mathrm{F}-\mathrm{CPB} /$ rock interface. This argument, which relates the increase in cement hydration products to a longer curing time, has been experimentally confirmed by the results of the TG/DTG analyses performed on the cemented pastes of F-CPB cured for 7 and $28 \mathrm{~d}$, which are shown in Figure 13. From this figure, it can be observed that the weight loss at temperatures of $110-200$ and $400-450^{\circ} \mathrm{C}$ of the $28 \mathrm{~d}$ samples is higher than those that are cured for only $7 \mathrm{~d}$. In other words, more cement hydration products form in the samples that are cured for a longer period of time.

Figure 12 also shows that the shear strength of the interface samples increases as the normal stress is increased. This is because a higher normal stress leads to increases in the contact area between the surface of the rock and the tailings particles, as well as between the

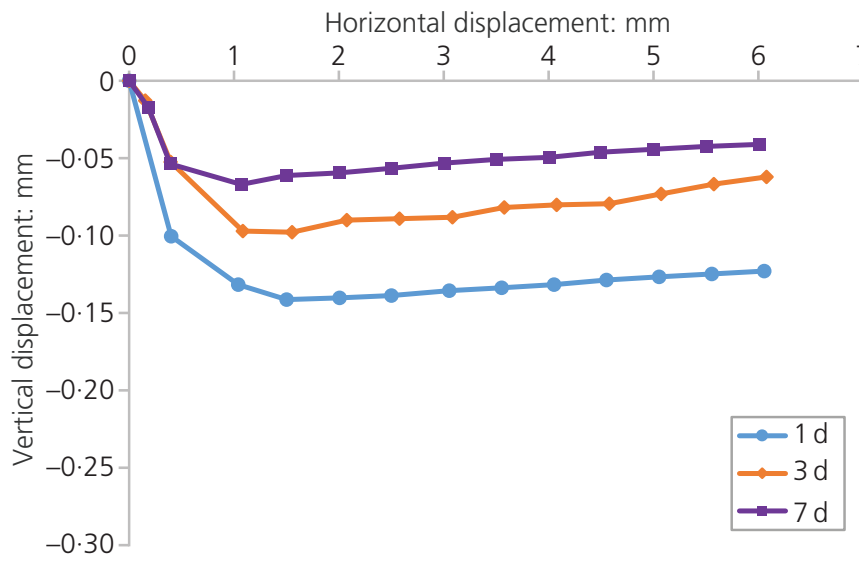

(a)

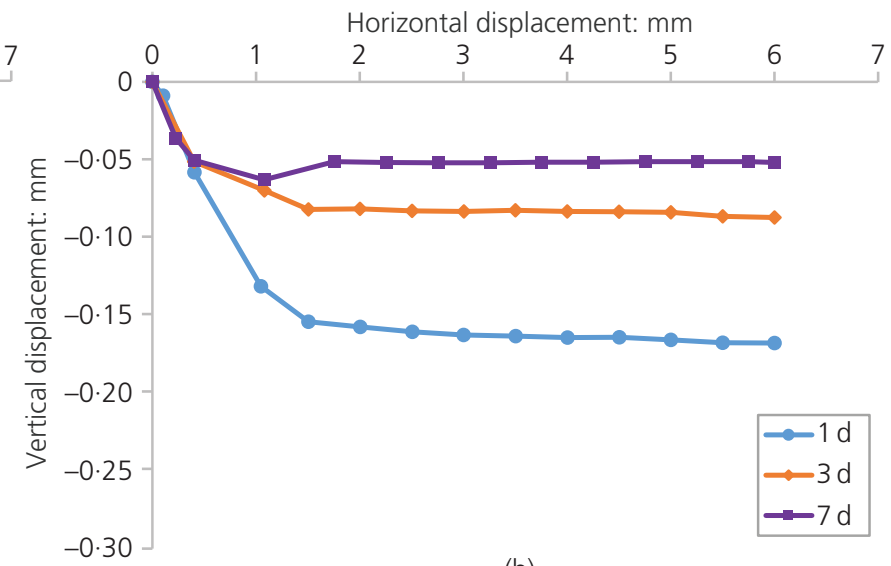

(b)

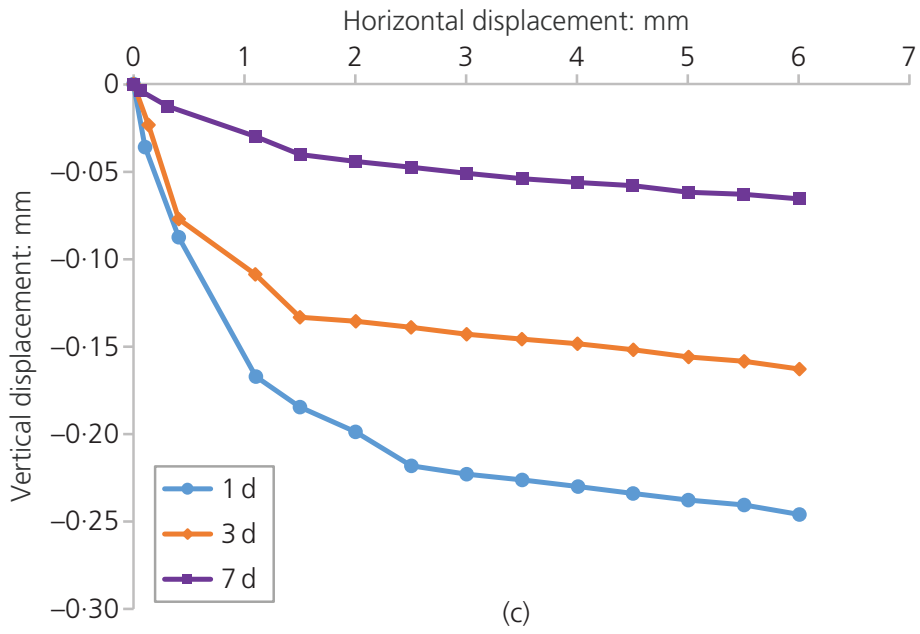

Figure 14. Vertical deformation-shear deformation plots of the $\mathrm{CPB} /$ rock interface with a $0 \cdot 3 \%$ fibre content for different curing times under different normal stresses: (a) $50 \mathrm{kPa}$; (b) $100 \mathrm{kPa}$; (c) $150 \mathrm{kPa}$ 
Table 6. Shear strength parameters of $1 \mathrm{~d}$ interface samples

\begin{tabular}{|c|c|c|c|c|c|}
\hline \multirow{2}{*}{ Sample number } & \multirow{2}{*}{ Interface type } & \multirow{2}{*}{ Tailings type } & \multirow{2}{*}{ Fibre content: \% } & \multicolumn{2}{|c|}{ Shear strength index } \\
\hline & & & & Cohesion, c: kPa & Internal friction angle, $\phi:^{\circ}$ \\
\hline 1 & CPB/rock & ST & 0.0 & $22 \cdot 2$ & $24 \cdot 2$ \\
\hline 2 & CPB/rock & ST & $0 \cdot 2$ & $25 \cdot 1$ & $25 \cdot 7$ \\
\hline 3 & CPB/rock & ST & $0 \cdot 3$ & $24 \cdot 2$ & $24 \cdot 7$ \\
\hline 4 & CPB/rock & ST & 0.5 & $10 \cdot 3$ & $27 \cdot 7$ \\
\hline 5 & CPB/rock & $\mathrm{ZT}$ & 0.0 & $15 \cdot 3$ & $26 \cdot 8$ \\
\hline 6 & CPB/rock & $\mathrm{ZT}$ & 0.5 & 7.9 & $27 \cdot 7$ \\
\hline
\end{tabular}

surface of the rock and the fibres. Consequently, the friction resistance between the tailings particles or fibres and the surface of the rock is increased (Nasir and Fall, 2008).

Figure 14 shows the vertical-displacement-against-shear-displacement curves of the F-CPB/rock interface with $0.3 \%$ fibre content for different curing times under different normal stresses. Under the same normal stress, the interface samples that have been cured for a shorter period of time are more deformed than the more aged samples. This is due to the fact that the degree of cement hydration of the former is lower than that of the latter. Accordingly, the F-CPB that has been cured for shorter periods of time has higher compressibility (Correia et al., 2015; Fall and Nasir, 2010; Nasir and Fall, 2008). Furthermore, it is evident in Figure 14 that under a low normal stress $(50 \mathrm{kPa})$, all of the samples show some dilatancy after the initial contraction behaviour. Moreover, the dilatancy is more pronounced with a longer curing time. The dilation behaviour observed at a low normal stress is due to the relative movement of the asperities. Under a low normal stress $(50 \mathrm{kPa})$, the asperities slide and roll on the shear plane, which cause dilatancy, while under a high normal stress $(150 \mathrm{kPa})$, the asperities are damaged during the shearing process, particularly with the crushing of large CPB particles, thus inhibiting the dilation or causing contraction. From Figure 14, it can be also observed that the amount of contraction is increased as the normal stress is increased. This is attributed to a greater reduction of the local voids due to a higher applied normal stress.

Figure 15, which shows the influence of curing time and fibre content on the shear strength of the F-CPB/rock interface for different normal stresses, indicates that the optimal fibre content

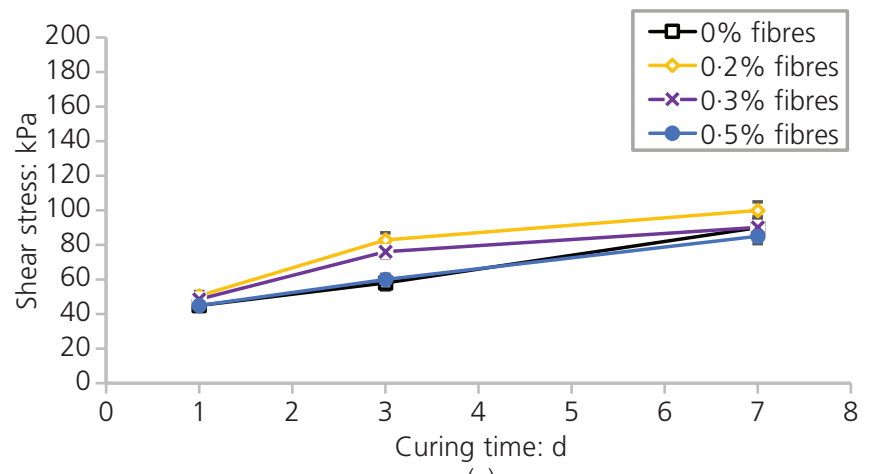

(a)

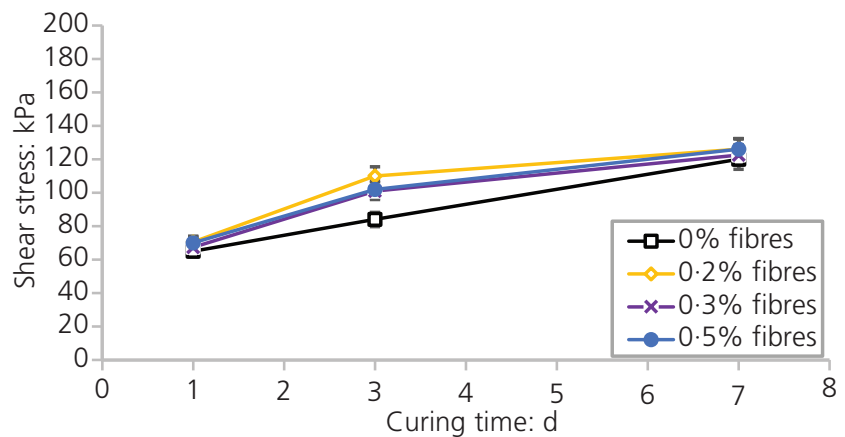

(b)

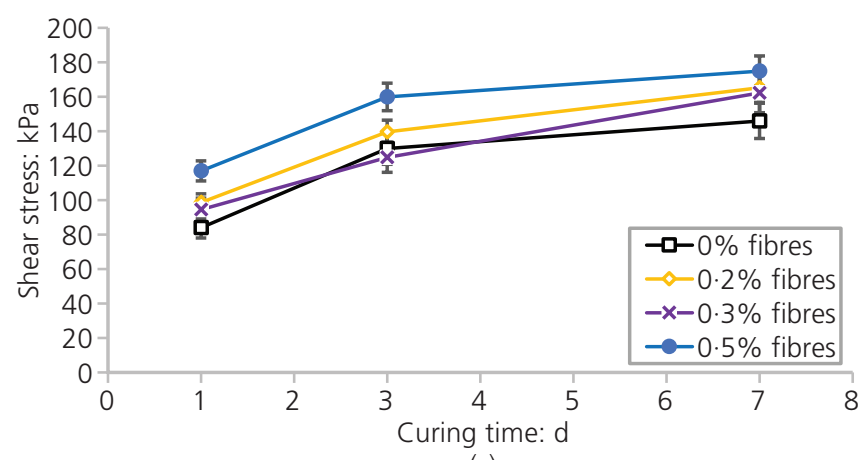

(c)

Figure 15. Effect of curing time and fibre content on the shear strength of the F-CPB/rock interface for different normal stresses (a) $50 \mathrm{kPa}$; (b) $100 \mathrm{kPa}$; (c) $150 \mathrm{kPa}$ 
Geotechnical Research

Volume 7 Issue 1
Characterisation of fibre-reinforced

backfill/rock interface through direct

shear tests

Xu, Fall, Alainachi and Fang (fibre content that results in the interface sample with the highest strength) is also a function of the normal stress applied at the interface, as well as of the curing time. For a high normal stress $(150 \mathrm{kPa})$, the interface samples with more fibres $(0 \cdot 5 \%)$ have a higher shear strength, whereas the samples that have a normal stress of $50 \mathrm{kPa}$ with $0 \cdot 2 \%$ fibres have higher shear strength. Moreover, the samples with fibres generally have higher shear strength than those without fibres, which could be due to the fact that the presence of fibres contributes to the strength of the asperities on the surface of the F-CPB. In other words, the fibres increase the amount of local normal or shear stress necessary to destroy the asperities fully. The fibres can bridge cracks in the asperities and delay their propagation, which would specifically result in an increase in the residual strength of the asperities. This would indicate that at a high normal stress $(150 \mathrm{kPa})$, fewer asperities are destroyed at the surface of the F-CPB with a $0.5 \%$ fibre content. Stronger and more asperities on the surface of the F-CPB are obviously associated with an increase in the interface friction strength (due to the increase in the internal friction angle) during the shear process, as also evidenced in Figures 15 and 16 (which will be discussed later). However, the presence of fibres at the interface should be regarded as an additional factor that contributes to the higher shear strength at the interface, as they increase the friction resistance at the interface.
Figures 16 and 17 show the effect of curing time and fibre content on the internal friction angle and cohesion of the samples and the shear envelopes of the F-CPB/rock interface, respectively. It is observed in Figure 16 again that all of the curves can be described well by using the Mohr-Coulomb failure criterion. Figures 16 and 17 also indicate that regardless of the length of the curing time, the interfaces of the samples with fibre generally have a larger internal friction angle than those without fibres. The processes responsible for the difference in the internal friction angle are the same as those described previously. Figure 17 shows that the interface adhesion or cohesion significantly increases as the curing time is increased, whereas the internal friction angle at the interface slightly increases with time. This is due to the increase in the degree of cement hydration with time, as explained previously. However, this figure also shows that the reduced cohesion due to the fibres at the interface is more pronounced at the more advanced ages $(7 \mathrm{~d})$. Indeed, the presence of fibres significantly reduces the cohesion at the interfaces of the $7 \mathrm{~d}$ samples irrespective of the fibre content. On the other hand, the difference in cohesion value between the interfaces of the samples with and without fibre content is obvious only when large volumes of fibres (around 0.5\%) are used when cured for shorter periods of time ( 1 and $3 \mathrm{~d}$ samples). This is because the presence of fibre particles at the surface of the rock not only reduces the effective

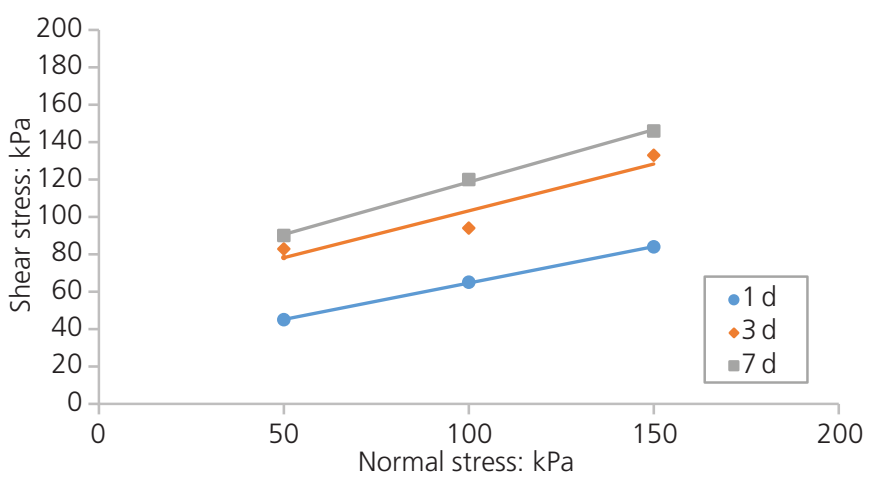

(a)

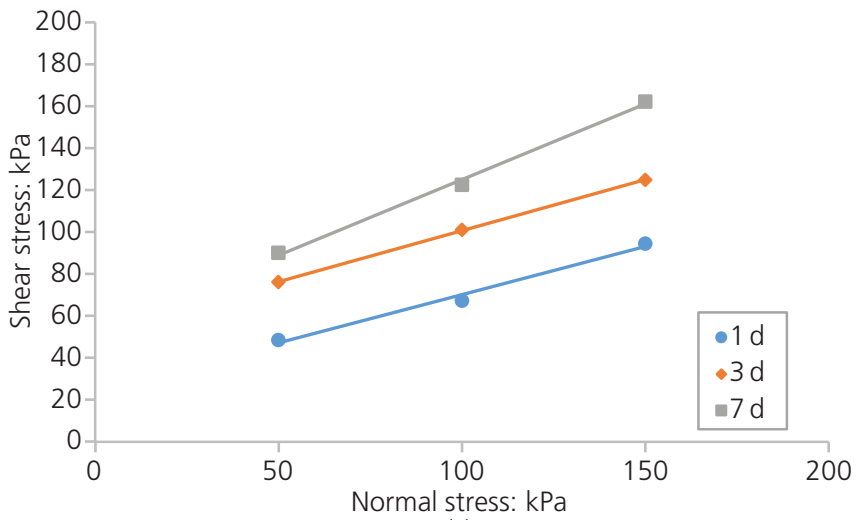

(c)

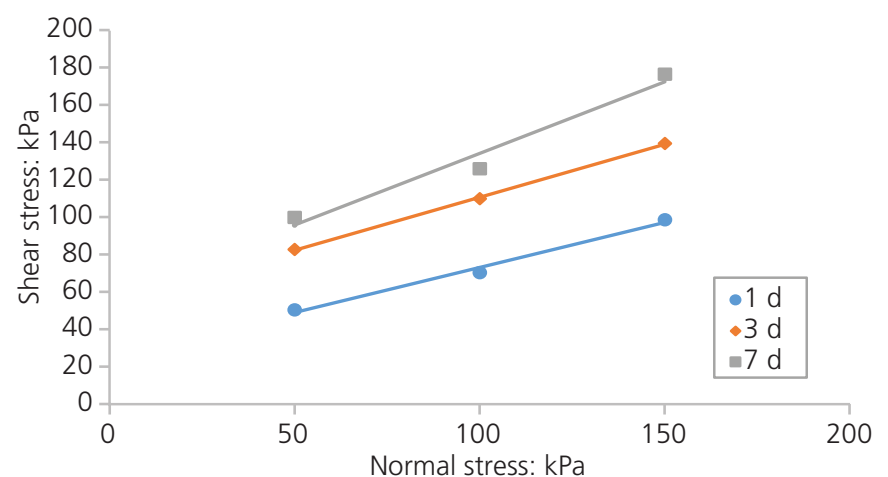

(b)

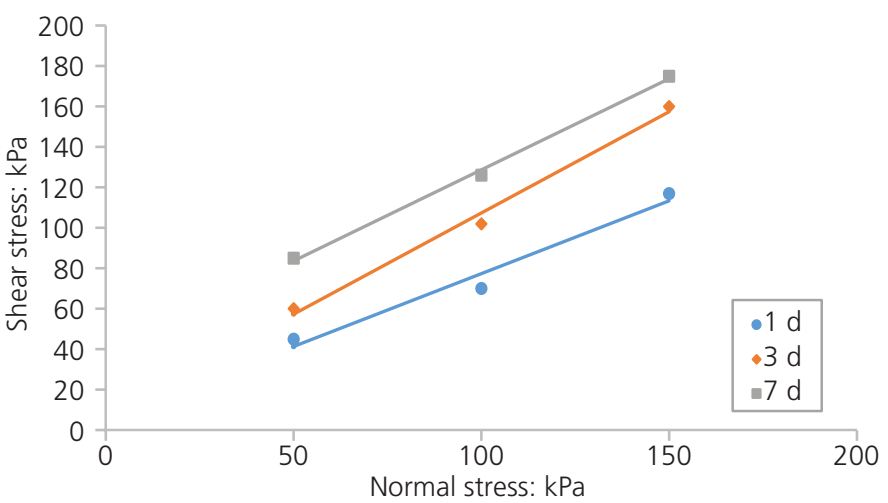

(d)

Figure 16. Shear envelopes of the F-CPB/rock interface against curing time for various fibre contents: (a) no fibre added; (b) $0.2 \%$ fibre content; (c) $0.3 \%$ fibre content; (d) $0.5 \%$ fibre content 


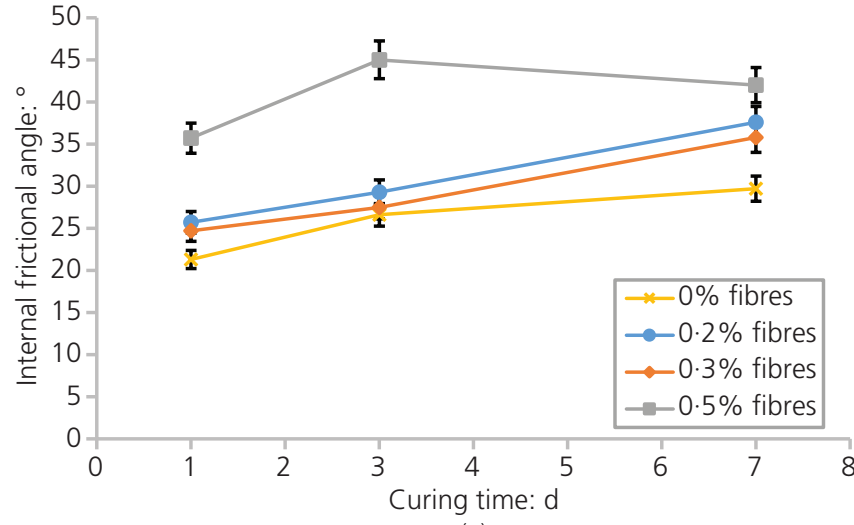

(a)

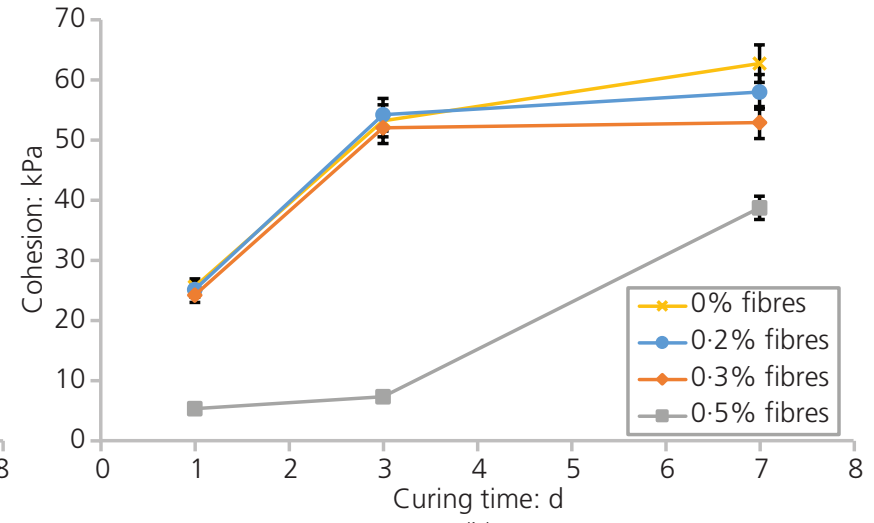

(b)

Figure 17. Effect of curing time and fibre content on the (a) internal friction angle and (b) cohesion of the F-CPB/rock interface

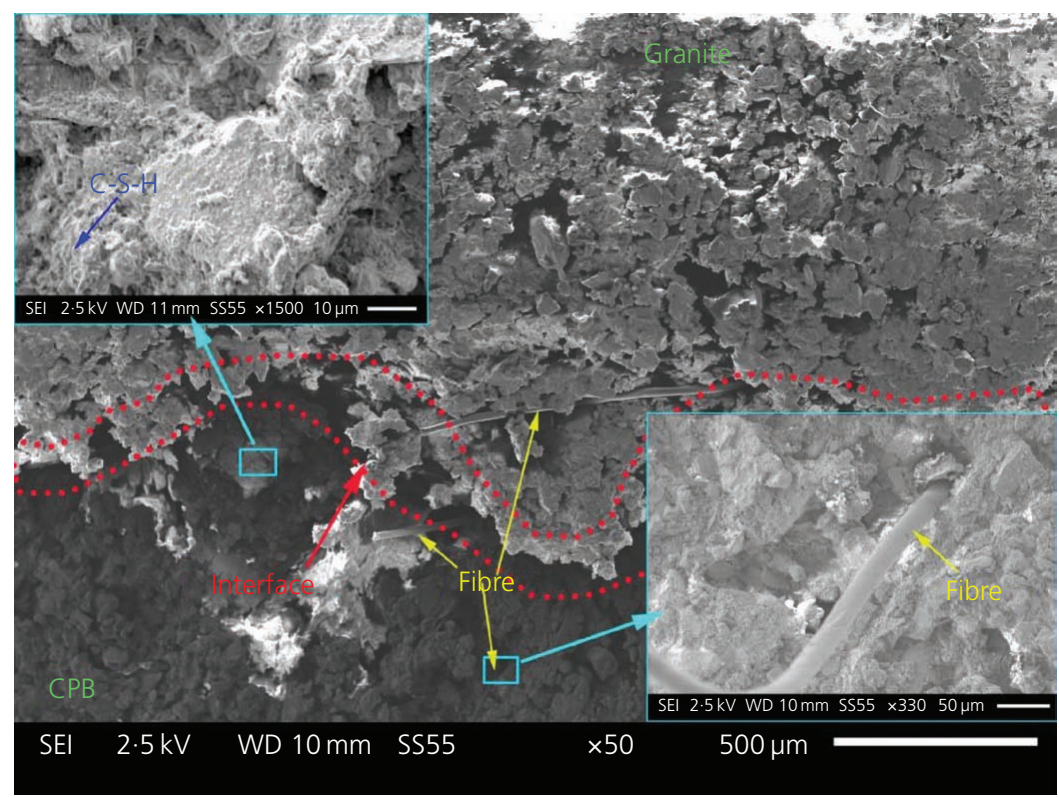

Figure 18. SEM image of F-CPB/rock interface with $0.5 \%$ fibre content

contact area between the cementitious matrix of the F-CPB and the rock but also reduces the volume of additional cement hydration products that can precipitate on the surface of the rock (to bind or cement the CPB material and the rock) with curing time. Consequently, the interfaces of the samples with a lower volume of fibres will have more cement hydration products on the surface of the rock and thus greater cementation (higher cohesion) at the advanced ages. This finding is supported by the SEM image of the interface of the $7 \mathrm{~d}$ sample with a fibre content of $0.5 \%$ in Figure 18 .

\section{Summary and conclusions}

In this paper, the experimental results of a study that aims to understand the shear behaviour and properties of the interface between rock and CPB with different fibre contents (F-CPB) are presented. The following conclusions are made based on the findings.
- The addition of fibres can improve the shear strength and residual shear strength at the interface between the F-CPB and the rock. However, a higher fibre content does not necessarily result in higher shear strength at the interface. There is a critical or optimal fibre content beyond which the shear characteristics (e.g. peak shear stress and residual shear strength) of the F-CPB/ rock interface are negatively affected. This optimal fibre content is a function of the curing time and normal stress applied at the interfaces of the samples studied.

- The addition of fibres reduces the contraction at the interface, and the degree of vertical deformation decreases as the fibre content is increased. This is because the presence of fibres inhibits the rearrangement and settlement of the tailings particles, which macroscopically decreases the compressibility and prevents the further deformation of the F-CPB material. 
- A longer curing time means higher shear strength due to the production of more cement hydration products. In addition, the shear-displacement-against-vertical-displacement behaviour at the F-CPB/rock interface is significantly affected by the applied normal stress.

- The chemical composition (sulfate content) of the pore water of the tailings also significantly affects the shear strength characteristics and deformation of the F-CPB/rock interface due to the inhibition of cement hydration by sulfate ions.

- The shear envelopes of the F-CPB/rock interface can be described well by the Mohr-Coulomb failure criterion, and the internal friction angle and cohesion are affected by the curing time and fibre content. The internal friction angle and the cohesion of the interfaces of samples with the same fibre content generally increase with time due to a higher degree of cement hydration. The presence of fibres reduces the interface cohesion, which is reduced even more significantly with a higher fibre content and a longer curing time.

\section{Acknowledgements}

The authors would like to thank the Natural Sciences and Engineering Research Council of Canada, University of Ottawa and Chinese Scholarship Council for their financial support.

\section{REFERENCES}

Akbulut S, Arasan S and Kalkan E (2007) Modification of clayey soils using scrap tire rubber and synthetic fibers. Applied Clay Science 38(1): $23-32$.

Cai Y, Shi B, Gao W, Chen FJ and Tang C (2006) Experimental study on engineering properties of fibre-lime treated soils. Chinese Journal of Geotechnical Engineering 28(10): 1283-1287.

Consoli NC and Vendruscolo MA (2009) Fiber reinforcement effects on sand considering a wide cementation range. Geotextiles and Geomembranes 27(3): 196-203.

Consoli NC, Montardo JP, Donato M and Prietto PD (2004) Effect of material properties on the behaviour of sand-cement-fibre composites. Ground Improvement 8(2): 77-90, https://doi.org/10.1680/grim.2004. 8.2.77.

Consoli NC, Bassani MAA and Festugato L (2010) Effect of fiberreinforcement on the strength of cemented soils. Geotextiles and Geomembranes 28(4): 344-351.

Consoli NC, Zortéa F and Souza MD (2011) Studies on the dosage of fiberreinforced cemented soils. Journal of Materials in Civil Engineering 23(12): 1624-1632.

Correia AAS, Oliveira PJV and Custódio DG (2015) Effect of polypropylene fibres on the compressive and tensile strength of a soft soil, artificially stabilised with binders. Geotextiles and Geomembranes 43(2): 97-106.

Diambra A and Ibraim E (2015) Fibre-reinforced sand: interaction at the fibre and grain scale. Géotechnique 65(4): 296-308, https://doi.org/10. 1680/geot.14.P.206.

Ercikdi B, Kesimal A, Cihangir F, Deveci H and Alp I (2009) Cemented paste backfill of sulphide-rich tailings: importance of binder type and dosage. Cement and Concrete Composites 31(4): 268-274.

Fall M and Nasir O (2010) Mechanical behaviour of the interface between cemented tailings backfill and retaining structures under shear loads. Journal of Geotechnical and Geological Engineering 26(6): 779-790.

Fall M and Pokharel M (2010) Coupled effects of sulphate and temperature on the strength development of cemented tailings backfills: Portland cement-paste backfill. Cement and Concrete Composites 32(10): 819-828.

Fall M and Samb SS (2009) Effect of high temperature on strength and microstructural properties of cemented paste backfill. Fire Safety Journal 44(4): 642-651.

Fall M, Adrien D, Célestin JC, Pokharel M and Touré M (2009) Saturated hydraulic conductivity of cemented paste backfill. Minerals Engineering 22(15): 1307-1317.

Fall M, Célestin JC and Touré M (2010) A contribution to understanding the effects of curing temperature on the mechanical properties of mine cemented tailings backfill. Engineering Geology 114(3): $397-413$.

Ghirian A and Fall M (2013) Coupled thermo-hydro-mechanical-chemical behaviour of cemented paste backfill in column experiments. Part I: physical, hydraulic and thermal processes and characteristics. Engineering Geology 164(1): 195-207.

Ghirian A and Fall M (2014) Coupled thermo-hydro-mechanical-chemical behaviour of cemented paste backfill in column experiments. Part II: mechanical, chemical and microstructural processes and characteristics. Engineering Geology 170(1): 11-23.

Gokhale AM and Underwood EE (1990) A general method for estimation of fracture surface roughness: Part I. Theoretical aspects. Metallurgical Transactions A 21(5): 1193-1199.

Hamidi A and Hooresfand M (2013) Effect of fiber reinforcement on triaxial shear behavior of cement treated sand. Geotextiles and Geomembranes 36(1): 1-9.

Li W and Fall M (2016) Sulphate effect on the early age strength and selfdesiccation of cemented paste backfill. Journal of Construction and Building Materials 106: 296-304.

Liu GS (2017) Required Strength Model of Cemented Backfill with Research on Arching Mechanism Considering Backfill-Rock Interaction. $\mathrm{PhD}$ thesis, University of Science and Technology Beijing, Beijing, China (in Chinese).

Liu Q, Liu D and Tian Y (2017) Numerical simulation of stress-strain behaviour of cemented paste backfill in triaxial compression. Engineering Geology 231(14): 165-175.

Ma G, Li Z and Yi X (2016) Macro-meso experiment of fiber-reinforced cement paste filling material. Journal of Beijing University of Technology 42(3): 406-412.

Mitchell RJ and Stone DM (1987) Stability of reinforced cemented backfills. Canadian Geotechnical Journal 24(2): 189-197.

Nasir O and Fall M (2008) Shear behaviour of cemented pastefill-rock interfaces. Engineering Geology 101(3-4): 146-143.

Nasir O and Fall M (2009) Modeling the heat development in hydrating CPB structures. Computers and Geotechnics 36(7): 1207-1218.

Orejarena L and Fall M (2008) Mechanical response of a mine composite material to extreme heat. Bulletin of Engineering Geology and the Environment 67(3): 387-396.

Pirapakaran K and Sivakugan N (2007) A laboratory model to study arching within a hydraulic fill stope. Geotechnical Testing Journal 30(6): 496-503.

Pokharel M and Fall M (2010) Coupled thermo-chemical effects on the strength development on slag-paste backfill materials. Journal of Materials in Civil Engineering 23(5): 511-525.

Prabakar J and Sridhar RS (2002) Effect of random inclusion of sisal fibre on strength behaviour of soil. Construction and Building Materials 16(2): 123-131.

Starcher RD and Liu C (2013) Mechanical behavior of cement- and cement-fiber-improved soft soils. In Geo-Congress 2013: Stability and Performance of Slopes and Embankments III (Meehan C, Pradel D, Pando MA and Labuz JF (eds)). American Society of Civil Engineers, Reston, VA, USA, pp. 2048-2057.

Tang C, Shi B, Gao W, Chen F and Cai Y (2007) Strength and mechanical behavior of short polypropylene fiber reinforced and cement stabilized clayey soil. Geotextiles and Geomembranes 25(3): 194-202. 
Geotechnical Research

Volume 7 Issue 1
Characterisation of fibre-reinforced backfill/rock interface through direct shear tests

Xu, Fall, Alainachi and Fang
Wang D, Tang C and Li J (2013) Shear strength characteristics of fiberreinforced unsaturated cohesive soils. Chinese Journal of Geotechnical Engineering 35(10): 1933-1940.

Wang Y, Fall M and Wu A (2016) Initial temperature-dependence of strength development and self-desiccation in cemented paste backfill that contains sodium silicate. Cement and Concrete Composites 67: 101-110.

Wu J and Zhang X (2011) Study on strength of polypropylene fiber reinforced expansive soil. Soil Engineering and Foundation 24(6): 71-73 (in Chinese).
Yi XW, Ma GW and Fourie A (2015) Compressive behaviour of fibrereinforced cemented paste backfill. Geotextiles and Geomembranes 43(3): 207-215.

Yilmaz T, Ercikdi B and Karaman K (2014) Assessment of strength properties of cemented paste backfill by ultrasonic pulse velocity test. Ultrasonics 54(5): 1386-1394.

Zaimoglu AS and Yetimoglu T (2012) Strength behavior of fine grained soil reinforced with randomly distributed polypropylene fibers. Geotechnical and Geological Engineering 30(1): 197-203.

\section{How can you contribute?}

To discuss this paper, please submit up to 500 words to the editor at journals@ice.org.uk. Your contribution will be forwarded to the author(s) for a reply and, if considered appropriate by the editorial board, it will be published as a discussion in a future issue of the journal. 